\title{
Aerosol recovery from large-volume reservoir delivery systems is highly dependent on the static properties of the reservoir
}

\author{
M.J. van der Veen, J.S. van der Zee
}

\begin{abstract}
Aerosol recovery from large-volume reservoir delivery systems is highly dependent on the static properties of the reservoir. M.J. van der Veen, J.S. van der Zee. (C)ERS Journals Ltd 1999.
\end{abstract}

ABSTRACT: In this study, the role of electrostatic fields on aerosol recovery from a system with a large collapsible reservoir $(30 \mathrm{~L})$ was investigated. In addition, the efficacy of the reservoir method for bronchial challenge procedures was assessed in vivo.

Aerosol recovery was determined by measuring the fraction of aerosol $(0.05 \%$ ${ }^{99 m}$ Tc-tagged human albumin solution) retrieved from the reservoir. Before aerosol recovery experiments, electrostatic fields in the reservoir were measured.

Aerosol recovery varied significantly with wall thickness of the reservoir and presence of an antistatic coating (range 6.0-70.3\%). A close inverse relationship was found between the mean electrostatic field in the reservoir and aerosol recovery. The nebulized provocative concentration of histamine causing a $20 \%$ fall in forced expiratory volume in one second in asthmatics was found to be approximately half that of a standard method when compared with the reservoir system (mean ratio 2.24 (95\% confidence interval, 1.60-3.12)).

Recovery from an aerosol delivery system with a relatively large collapsible aerosol reservoir was highly dependent on the electrostatic field in the reservoir. In these systems the use of electrostatic field dissipative material for the reservoir is therefore recommended.

Eur Respir J 1999; 13: 668-672.
Dept of Pulmonology, Academic Medical Centre, University of Amsterdam, Amsterdam, the Netherlands.

Correspondence: J.S. van der Zee

Academic Medical Centre

University of Amsterdam

Dept of Pulmonology, F4-208

P.O. Box 22700

1100 DE Amsterdam

The Netherlands

Fax: 31206917584

Keywords: Aerosol delivery

nebulizer

reservoir

static field

Received: September 11997

Accepted after revision October 261998

Supported by the Netherlands Asthma Foundation (grant 93.47)
For the administration of substances with high costs or limited availability by inhalation (e.g. neurokinin A [1]), a highly efficient method for aerosol generation and deposition in the airways is required. However, most jet nebulizers used for this purpose require fill volumes of $\geq 10$-times the aerosolized volume for proper functioning [2]. In addition, in these conventional jet nebulizers, solvent is lost during nebulization by the concomitant process of evaporation, hampering the accurate calibration of nebulizer output [3]. Also, in most methods for aerosol delivery to the airways, the aerosol is generated continuously during tidal breathing with resulting loss of aerosol during expiration. This specific problem can be circumvented by using a dosimeter [2], but its high cost impedes widespread use. Moreover, by using a dosimeter, increased aerosol deposition in the throat and central airways will occur as a result of the decreased inhalation time with increased flow that is employed with this technique $[4,5]$.

The efficiency of aerosol generation and delivery to the airways can be improved by using a nebulizer with small fill volume and residual volume [6] in combination with an aerosol reservoir [6-10]. In these systems, minimal initial fluid volumes are required and the whole volume of the generated aerosol will be inhaled without loss of aerosol during expiration. In the ambient dry atmosphere inside the aerosol reservoir, the aerosol droplets will evaporate de- pending on relative humidity and solute content [8]. Under optimal drying conditions it is possible to generate dry particles $[6,8,9]$. Depending on choice of the solute concentration and drying conditions, the diameter of the aerosol particles will decrease during evaporation [8], improving penetration in the peripheral airways after inhalation with increased deposition after hygroscopic growth [8, 10]. This mechanism has been described to be particularly advantageous for the alveolar targeting of aerosols in certain diagnostic and therapeutic applications $[8,10,11]$.

In this report the characteristics of an aerosol delivery system with a large collapsible aerosol reservoir $(30 \mathrm{~L})$ and a limited drying effect intended for bronchial deposition of aerosol is described. This system has previously been described as resulting in efficient aerosol deposition in the lungs (range 49-62\%) [6]. However, when using this system for allergen challenge, an unexpectedly low aerosol recovery was found when conventional reservoirs made of polyethylene were used. This finding indicated a possible strong inhibiting influence of electrostatic fields on aerosol recovery from the reservoir, as was earlier suggested by MATTHYs et al. [9]. Aerosol recovery characteristics of this aerosol delivery system were therefore validated in detail by varying electrostatic properties by using various materials for the reservoir. In addition, the efficacy of the reservoir method for bronchial challenge procedures was assessed in vivo. 


\section{Materials and methods}

\section{Aerosol delivery systems}

A reservoir aerosol delivery system as described previously by BeL et al. [6] was used (fig. 1). This system is equipped with a highly efficient jet nebulizer without baffle and with small residual volume $(<0.1 \mathrm{~mL})$ (Mallinckrodt Diagnostica, Petten, the Netherlands). The aerosol is generated by means of compressed dry air from an initial volume of $0.5 \mathrm{~mL}$ fluid in $1 \mathrm{~min}$ at an airflow rate of $3 \mathrm{~L} \cdot \mathrm{min}^{-1}$. The aerosol is stored in a plastic collapsible reservoir (see Aerosol recovery experiments) containing approximately $30 \mathrm{~L}$ of dry air (relative humidity $<10 \%$ ) at ambient air temperature and pressure. The aerosol is recovered from the reservoir through an outlet, either by inhalation during tidal breathing via a three-way valve box or by using a regulated vacuum pump $\left(10 \mathrm{~L} \cdot \mathrm{min}^{-1}\right)$. For comparison, a standard aerosol delivery system frequently employed in bronchial challenge procedures [2] was used. This system consists of a conventional jet nebulizer with a required fill volume of approximately $3 \mathrm{~mL}$ (DeVilbiss 646, Somerset, PA, USA) attached to an inspiratory and expiratory three-way valve box. The nebulizer was calibrated by measuring weight loss at an output of $0.13 \mathrm{~mL} \cdot \mathrm{min}^{-1}$ at a flow rate of approximately 4 $\mathrm{L} \cdot \mathrm{min}^{-1}$.

\section{Aerosol particle size measurements}

Aerosol particle size measurements were performed in aerosols generated from standard allergen dilution fluid (phosphate-buffered saline (PBS), $0.5 \%$ phenol, $0.03 \%$ human serum albumin (HSA); ALK Benelux, Groningen, the Netherlands), histamine diphosphate-PBS (32 $\left.\mathrm{mg} \cdot \mathrm{mL}^{-1}\right)$, and saline $(0.9 \% \mathrm{NaCl})$. The mass median diameter (MMD) and count median diameter (CMD) of the aerosol particles (range $0.5-10 \mu \mathrm{m}$ ) was determined by a laser particle and droplet analyser (Metone, Grants Pass, OR, USA). In this device, aerosol particles pass through a He-Ne laser beam

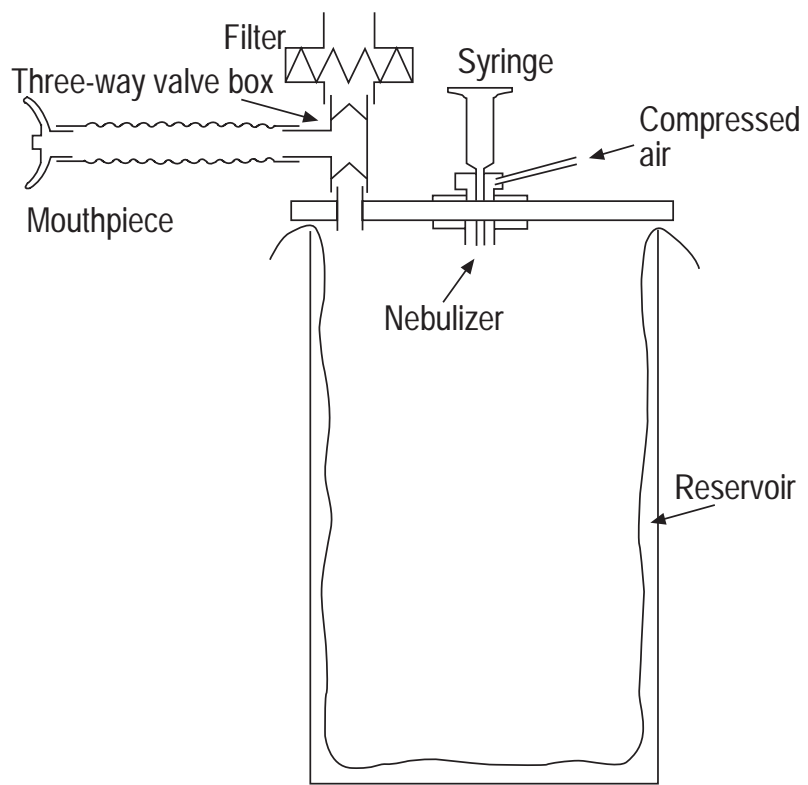

Fig. 1. - Schematic representation of the reservoir bronchial aerosol delivery system. and the light refracts at different angles with different particle size. The particle size of aerosols generated with the reservoir method was measured by sampling through the outlet of the electrostatic dissipative reservoir, directly after generation of the aerosol and after 3 and 6 min. Measurements of aerosols generated with the standard method were performed by sampling at the orifice of the nebulizer during continuous nebulization. All experiments were performed in duplicate.

\section{Aerosol recovery experiments}

Aerosol recovery experiments were performed with the reservoir system, equipped with different types of collapsible reservoirs. Handling of the reservoirs, including opening and installation in the reservoir container, were standardized as far as possible. Reproducibility of the recovery procedure per se without the influence of electrostatic charge was determined with electrostatic dissipative reservoirs. The reservoirs were plastic bags $(30 \mathrm{~L})$ made of polyethylene (thickness 30 and $100 \mu \mathrm{m}$; Van der Windt Verpakkingen, Honselersdijk, the Netherlands; 50 and 150 $\mu \mathrm{m}$; VPP Industries, Bussum, the Netherlands). The antistatic reservoir consisted of polyethylene with an antistatic coating (150 $\mu \mathrm{m}$; Richmond Antistatic (RCAS) 1206, Richmond Redlands, CA, USA).

Technetium-99m ( ${ }^{99 m}$ Tc)-labelled HSA was added to the standard allergen dilution fluid described above with a final HSA concentration of $0.05 \%$. The radioactivity of the syringe containing a $0.5 \mathrm{~mL}$ sample was measured before nebulization (typically $15 \mathrm{MBq}$ ). After generation of the aerosol, the reservoir was emptied by means of a regulated vacuum $\left(10 \mathrm{~L} \cdot \mathrm{min}^{-1}\right)$ in approximately $3 \mathrm{~min}$ through a submicron filter (Artec, Indianapolis, IN, USA) connected to the outlet of the reservoir. Subsequently, the radioactivity of the syringe, reservoir, and filter were measured and together accounted for $92.7 \pm 2.6 \%($ mean $\pm S D ; n=9)$ of the initial radioactivity. Aerosol recovery from the reservoir was expressed as the percentage of the total amount of radioactivity initially stored in the reservoir, i.e. initial activity of the syringe minus the remaining activity in the syringe. The results were calculated from activity in the outer filter divided by activity deposited in the reservoir.

\section{Electrostatic field measurements}

Electrostatic field measurements inside the reservoir were performed with an electrostatic field meter (Anderson Effects Inc., Mentone, CA, USA). Readings were taken at four opposite sides and at four different levels just before aerosol recovery experiments. Electrostatic field values were expressed as the mean of the absolute voltages (i.e. mean static value).

\section{Bronchial histamine challenges}

Two bronchial histamine challenges were performed in seven subjects (six male; mean age 30.6 yrs (range 23-41 yrs)) with mild-to-moderate asthma in a crossover study design at the same time of day on two consecutive days. Patient characteristics are shown in table 1.

In four patients, bronchial histamine challenge was started with the reservoir aerosol delivery system (reservoir method) and in three patients with the standard aerosol 
Table 1. - Patient characteristics

\begin{tabular}{lcccc}
\hline $\begin{array}{l}\text { Patient } \\
\text { No. }\end{array}$ & $\begin{array}{c}\text { Age } \\
\text { yrs }\end{array}$ & $\begin{array}{c}\text { FEV1 day 1/2 } \\
\text { \% pred }\end{array}$ & $\begin{array}{c}\text { PC20 histamine } \\
\mathrm{mg} \cdot \mathrm{mL}^{-1}\end{array}$ & Medication \\
\hline 1 & 41 & $105 / 103$ & 2.4 & $\mathrm{~B}$ \\
2 & 27 & $111 / 110$ & 6.6 & $\mathrm{~B}$ \\
3 & 32 & $90 / 90$ & 2.8 & $\mathrm{~B}$ \\
4 & 34 & $97 / 97$ & 3.3 & $\mathrm{~B}$ \\
5 & 30 & $114 / 115$ & 5.6 & $\mathrm{BC}$ \\
6 & 27 & $92 / 96$ & 0.3 & $\mathrm{BC}$ \\
7 & 23 & $103 / 102$ & 3.3 & $\mathrm{BC}$ \\
\hline
\end{tabular}

FEV1: forced expiratory volume in one second; PC20: provocative concentration causing a $20 \%$ fall in FEV1; C: inhaled corticosteroids; $\mathrm{B}$ : inhaled $\beta_{2}$-agonists p.r.n.

delivery system (standard method). Informed consent was obtained from all patients.

Both bronchial histamine challenges were performed according to a standardized procedure [2]. With the reservoir method, an aerosol was generated from an initial volume of $0.5 \mathrm{~mL}$ histamine diphosphate in PBS in a reservoir made of electrostatic field dissipative material (see Aerosol recovery experiments). The entire volume of the reservoir was inhaled in approximately $3 \mathrm{~min}$. With the standard method, a histamine aerosol was generated continuously during $2 \mathrm{~min}$ of tidal breathing (i.e. aerosol output $0.26 \mathrm{~mL}$ ). With both methods, doubling provocative concentrations of histamine diphosphate in PBS were inhaled (range $0.015-32 \mathrm{mg} \cdot \mathrm{mL}^{-1}$ ) with the nose clipped until a fall in the forced expiratory volume in one second (FEV1) of $>20 \%$ of baseline value FEV 1 (PC20) (mean of three measurements) occurred. Spirometry was performed by using a dry rolling-seal spirometer (SensorMedics, Bilthoven, the Netherlands) at 30, 90 and $180 \mathrm{~s}$ after inhalation and the lowest value of FEV1 was used for analysis. The nebulized PC20 was calculated by log-linear interpolation [2].

\section{Statistical analysis}

Linear regression and correlation was performed with Graphpad software (San Diego, CA, USA). Histamine threshold data were log-transformed to obtain normal distribution and differences were expressed by mean ratio.

\section{Results}

\section{Aerosol particle size}

The MMD, CMD and geometric standard deviation (GSD) of the aerosol particles generated with the reservoir

Table 2. - Influence of reservoir wall thickness and static field on aerosol recovery

\begin{tabular}{lcc}
\hline $\begin{array}{l}\text { Polyethylene wall } \\
\text { thickness } \mu \mathrm{m}\end{array}$ & Recovery \% & Mean static value \\
\hline 30 & $6.0(4.8)$ & $2.94(1.9)$ \\
50 & $49.4(4.5)$ & $0.95(0.2)$ \\
100 & $44.0(6.8)$ & $0.97(0.6)$ \\
150 & $57.4(8.5)$ & $0.58(0.5)$ \\
$150+$ antistatic coating & $70.3(1.3)$ & $<0.1(<0.1)$ \\
\hline
\end{tabular}

Mean (SD) of 3-6 measurements. method from standard allergen dilution fluid (MMD 4.3 $\mu \mathrm{m}$; CMD $0.65 \mu \mathrm{m}$, GSD 2.2), histamine diphosphate 32 $\mathrm{mg} \cdot \mathrm{mL}^{-1}$ (MMD 4.2 $\mu \mathrm{m}$; CMD $0.65 \mu \mathrm{m}$, GSD 2.1), and saline (MMD 4.1 $\mu \mathrm{m}$; CMD $0.67 \mu \mathrm{m}$, GSD 2.1) were found to be similar. Moreover, no significant differences were found between measurements performed directly after nebulization and after 3 and 6 min.

The particle size distributions of aerosols generated with the standard method (De Vilbiss 646) were found to be similar as compared with the reservoir method (e.g. allergen dilution fluid: MMD $4.3 \mu \mathrm{m}$; CMD $0.64 \mu \mathrm{m}$, GSD 2.2).

Aerosol recovery in relation to the electrostatic field in the reservoir

The efficiency of the nebulizer, i.e. the relation between radioactivity in the syringe before and after nebulization, was found to be high and within a narrow range (82.6 $\pm 1.3 \%$ (mean $\pm \mathrm{SD} ; \mathrm{n}=9)$ ). Aerosol recovery, as calculated by using the remaining activity in the reservoir, was found to be higher than when calculated with the activity in the outlet filter. This difference, however, was small and similar in all experiments (mean difference $8.8 \pm 3.2 \%$ (mean \pm $\mathrm{SD}$ ); $\mathrm{n}=9$ ). The seeming loss of activity was probably caused by a reduced counting efficiency owing to the geometry of the reservoir and filter. Aerosol recovery results are conservatively calculated from activity in the outlet filter.

Aerosol recovery varied significantly with the electrostatic field in the reservoir immediately before nebulization (table 2). Wall thickness of the reservoir appeared to be a significant determinant of electrostatic charge. The lowest aerosol recovery (mean of six experiments $6.0 \%$, SD 4.8 ) was found with reservoirs made of thin polyethylene (30 $\mu \mathrm{m})$. The highest recovery was with electrostatic field dissipative coated material (mean of four experiments $70.3 \%$, sD 1.3). In reservoirs made of electrostatic field dissipative material, no significant electrostatic fields $(>0.1 \mathrm{kV})$ were detected (table 2). A significant inverse relationship was found between the electrostatic field in the reservoir and aerosol recovery (fig. 2).

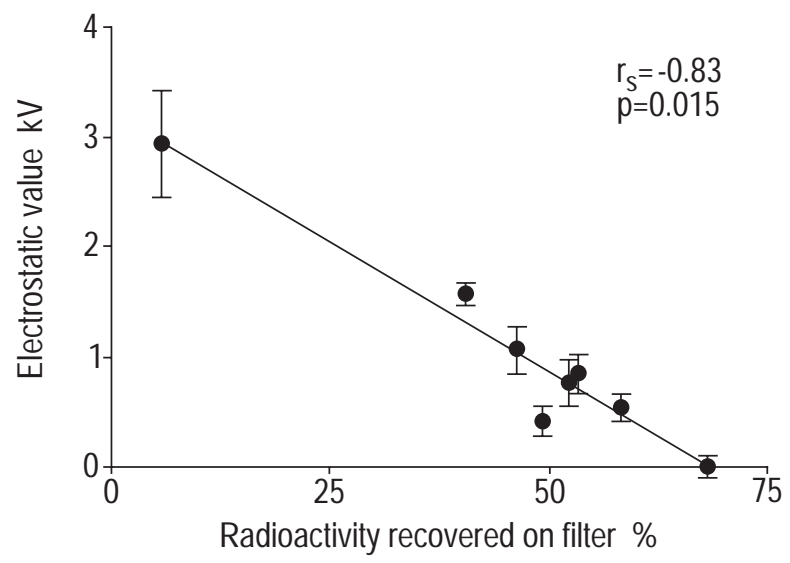

Fig. 2. - Relationship between aerosol recovery and the electrostatic field in the reservoir. Results of eight consecutive experiments performed on the same day under identical conditions. Data shown as mean \pm SEM (16 readings). 


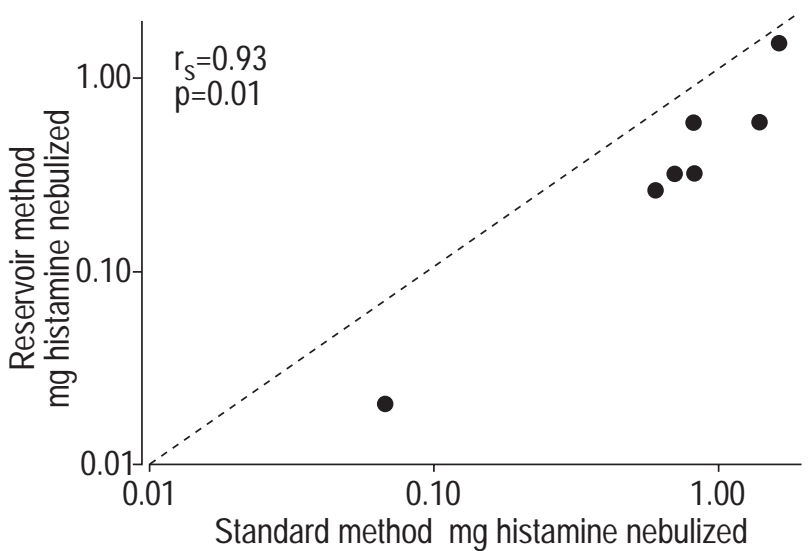

Fig. 3. - Amount of histamine nebulized in order to obtain $20 \%$ decrease in forced expiratory volume in one second. Results as found with the standard method versus the reservoir method in seven asthmatic patients. - - : line of identity.

\section{Bronchial histamine challenge}

For all seven patients tested, the $\mathrm{PC} 20$ was found to be lower with the reservoir method than with the standard method (fig. 3). The mean difference in nebulized histamine between both methods, expressed by the mean ratio, was found to be a factor of 2.24 (95\% confidence interval (CI) 1.60-3.12). A significant correlation between the outcomes of both methods was found for the group of patients $\left(\mathrm{r}_{\mathrm{s}}=0.93, \mathrm{p}=0.007\right)$.

\section{Discussion}

The present report describes the characteristics of an aerosol delivery system equipped with a highly efficient nebulizer with a small fill volume $(0.5 \mathrm{~mL})$, a small residual volume $(<0.1 \mathrm{~mL})$ and a large collapsible aerosol reservoir $( \pm 30 \mathrm{~L})$. Aerosol recovery from the reservoir was found to be highly dependent on the electrostatic properties of the reservoir. The strong inhibiting influence of electrostatic fields on aerosol recovery was somewhat unexpected in view of the relatively large distance between the reservoir wall and the majority of the aerosol particles (diameter of the reservoir $30 \mathrm{~cm}$ ). A low aerosol recovery of $6 \%$ was found when reservoirs made of thin polyethylene were used, with high electrostatic fields measured before aerosol recovery. In contrast, with reservoirs made of electrostatic field dissipative material (polyethylene + antistatic coating) the aerosol recovery was found to improve to $70 \%$.

Comparison of bronchial histamine challenges performed with the reservoir method, with a reservoir made of electrostatic field dissipative material, and a standard method for bronchial challenge, revealed that with the reservoir method significantly less histamine had to be nebulized to obtain the same bronchoconstrictor effect. This difference was found to be approximately two-fold. In view of the similar aerosol characteristics these differences can most likely be attributed to aerosol loss during the expiratory phase (expiration plus expiration pause) of tidal breathing in the standard method.

The direct particle size measurements confirm a limited drying effect in the reservoir under the conditions chosen.
The increase in relative humidity $(<10 \%$ to $70-80 \%)$ immediately after nebulization in the reservoir indicates a 60 $70 \%$ loss of water corresponding to a $30 \%$ decrease in particle diameter. The equilibrium is determined by the maximal water content of the $30 \mathrm{~L}$ of dry air, and hygroscopic activity of salt solutions (maximal relative humidity above saturated saline is approximately $70 \%$ ). In both the standard and reservoir method, initial evaporation of aerosol particles will occur as a consequence of the high velocity dry air stream used in the process of nebulization. The effect of evaporation on the resulting aerosol particle size will depend on the original particle size, its solute content and the volume of dry air in the reservoir [12].

Aerosols, as generated in this study, appear to be appropriate for bronchial deposition. Theoretically, a $1 \%$ solute content of the aerosol fluid, with a density similar to the solvent, gives rise to dry particles of, at most, a factor 4.3-times smaller than the original aerosol droplets after complete evaporation [12]. With lower solute densities and concentration, the effect of evaporation in the reservoir on aerosol particle size increases. An additional "drying" effect has previously been described to result in increased alveolar deposition of hygroscopic aerosol particles, which can be highly advantageous for several therapeutic (e.g. pentamidine [10]) and diagnostic applications (e.g. ${ }^{99 \mathrm{~m}} \mathrm{Tc}$ [8]) targeted at the alveolar compartment.

In conclusion, aerosol recovery from an aerosol delivery system with a relatively large collapsible reservoir was found to be highly dependent on the electrostatic properties of the reservoir. In these systems the use of electrostatic field dissipative material for the reservoir is therefore recommended. Bronchial responses to histamine in vivo as assessed with the reservoir method are at least similar to standard methods for bronchial challenge.

The high efficiency of the reservoir aerosol delivery system, owing to its small fill and residual volumes and the absence of expiratory aerosol loss, will be advantageous for the administration of substances with low availability or high costs by inhalation [1]. This beneficial characteristic, together with the reported high reproducibility of aerosol deposition in the airways [9], makes this system attractive as an alternative to more expensive dosimeter equipped systems.

Acknowledgements. The authors thank C. de Jong, Department of Nuclear Medicine, Academic Medical Centre, University of Amsterdam for technical assistance.

\section{References}

1. Cheung D, Timmers MC, Zwinderman AH, Den Hartigh J, Dijkman JH, Sterk PJ. Neutral endopeptidase activity and airway hyperresponsiveness to neurokinin A in asthmatic subjects in vivo. Am Rev Respir Dis 1993; 148: 1467-1473.

2. Sterk PJ, Fabbri LM, Quanjer PH, et al. Airway responsiveness: standardized challenge testing with pharmacological, physical and sensitizing stimuli in adults. Report Working Party Standardization of Lung Function Tests. European Community for Steel and Coal. Official Statement of the European Respiratory Society. Eur Respir J 1993; 6: Suppl. 16, 53-83. 
3. Dennis JH, Stenton SC, Beach JR, Avery AJ, Watters EH, Hendrick DJ. Jet and ultrasonic nebuliser output: use of a new method for direct measurement of aerosol output. Thorax 1990; 45: 728-732.

4. Ryan G, Dolovich MB, Obminski G, et al. Standardization of inhalation provocation tests: influence of nebulizer output, particle size, and method of inhalation. $J$ Allergy Clin Immunol 1981; 67: 156-161.

5. Ryan G, Dolovich MB, Roberts RS, et al. Standardization of inhalation provocation tests: two techniques of aerosol generation and inhalation compared. Am Rev Respir Dis 1981; 123: 195-199.

6. Bel EH, Van der Veen H, Kramps JA, Dijkman JH, Sterk PJ. Maximal airway narrowing to inhaled leukotriene $\mathrm{D}_{4}$ in normal subjects: comparison and interaction with methacholine. Am Rev Respir Dis 1987; 136: 979-984.

7. Thomas SH, Langford JA, George RD, Geddes DM. Improving the efficiency of drug administration with jet nebulisers. Lancet 1988; i: 126.

8. Miller RF, Jarritt PH, Lui D, Kidery J, Semple SJ, Ell PJ. The APE nebuliser - a new delivery system for the alveolar targeting of particulate technetium-99m diethylene triamine penta-acetic acid. Eur J Nucl Med 1991; 18: 164-170.
9. Matthys H, Knoch M, Eltschka R. A new aerosol device for bronchial provocation tests. Respiration 1993; 60: 343-350.

10. Everard ML, Milner AD. A drying chamber for use with small volume jet nebulizers. Respir Med 1995; 89: $567-$ 569.

11. Brain JD, Valberg PA. Deposition of aerosol in the respiratory tract. Am Rev Respir Dis 1979; 120: 13251373.

12. Swift DL. Aerosol characterization and generation. In: Moren F, Newhouse NT, Dolovich MB, eds. Aerosols in Medicine: Principles. Diagnosis and Therapy. Oxford, Elsevier, 1985; pp. 53-76.

13. Sterk PJ, Plomp A, Van de Vate JF, Quanjer PH. Physical properties of aerosols produced by several jet- and ultrasonic nebulizers. Bull Eur Physiopathol Respir 1984; 20: $65-72$

14. Clay MM, Clarke SW. Effect of nebulised aerosol size on lung deposition in patients with mild asthma. Thorax 1987; 42: 190-194.

15. Sterk PJ, Plomp A, Crobach MJ, Van de Vate JF, Quanjer $\mathrm{PH}$. The physical properties of a jet nebulizer and their relevance for the histamine provocation test. Bull Eur Physiopathol Respir 1983; 19: 27-36. 